Department of International Health, Rollins School of Public Health of Emory University, Atlanta, Georgia A C Haddix

Injury Prevention Service, Oklahoma State Department of Health, Oklahoma City, Oklahoma

$S$ Mallonee

M R Douglas

National Center for Injury Prevention and Control, Centers for Disease Control and Prevention, Atlanta, Georgia

$\mathrm{R}$ Waxweiler

Correspondence to: Dr Anne C Haddix, Department of International Health, Rollins School of Public Health of Emory University, 1518 Clifton Road, Atlanta, GA 30322, USA

achaddi@sph.emory.edu

Reprint requests to: Sue Mallonee, Injury Prevention Service-0307, Oklahoma State Department of Health, 1000 NE 10th St, Oklahoma City, OK 73117-1299,USA Suem@health.state.ok.us

\title{
Cost effectiveness analysis of a smoke alarm giveaway program in Oklahoma City, Oklahoma
}

\author{
A C Haddix, S Mallonee, R Waxweiler, M R Douglas
}

\begin{abstract}
Objective-To estimate the cost effectiveness of the Lifesavers Residential Fire and Injury Prevention Program (LRFIPP), a smoke alarm giveaway program. Setting-In 1990, the LRFIPP distributed over 10000 smoke alarms in an area of Oklahoma City at high risk for residential fire injuries. The program also included fire prevention education and battery replacement components.

Methods-A cost effectiveness analysis was conducted from the societal and health care systems perspectives. The study compared program costs with the total costs of medical treatment and productivity losses averted over a five year period. Fatal and non-fatal residential fire related injuries prevented were estimated from surveillance data. Medical costs were obtained from chart reviews of patients with fire related injuries that occurred during the pre-intervention period.

Results-During the five years postintervention, it is estimated that the LRFIPP prevented 20 fatal and 24 nonfatal injuries. From the societal perspective, the total discounted cost of the program was $\$ 531000$. Total discounted net savings exceeded $\$ 15$ million. From the health care system perspective, the total discounted net savings were almost $\$ 1$ million and would have a net saving even if program effectiveness was reduced by $64 \%$.

Conclusions-The program was effective in reducing fatal and non-fatal residential fire related injuries and was cost saving. Similar programs in other high risk areas would be good investments even if program effectiveness was lower than that achieved by the LRFIPP.

(Injury Prevention 2001;7:276-281)
\end{abstract}

Keywords: cost effectiveness; fires; burns; smoke alarms

The United States has one of the highest fire related death rates of all industrialized nations and residential fires account for an estimated $70 \%$ to $80 \%$ of such deaths. ${ }^{1-4}$ In 1998 , there were 3250 deaths and 17175 injuries nationally from residential fires. ${ }^{5}$ Mortality risk is greatest among the very young, the elderly, persons with disabilities, and persons with low socioeconomic status. ${ }^{5-9}$ In addition to the impact of fatalities, there are long term physical, emotional, and economic effects for those who survive residential fires with severe burns. The average cost associated with a burn injury requiring hospitalization has been estimated at over $\$ 35000$ and property losses from the 381500 residential fires that occurred in the United States in 1998 were estimated at $\$ 4.4$ billion dollars. ${ }^{35}$

The absence of a functional smoke alarm is known to be a major risk factor for residential fire fatalities. ${ }^{7}$ Corroborative reports have suggested that smoke alarms reduce fire related morbidity and mortality, and the American Medical Association's Council on Scientific Affairs estimated that smoke alarms could reduce the death rate for residential fires by $50 \% .{ }^{10}$ However, as recently as 1990 , about $80 \%$ of residential fire deaths occurred in homes without working smoke alarms. ${ }^{11}$

A large smoke alarm giveaway and educational program in Oklahoma City was the first residential prevention program to evaluate whether increasing the prevalence of alarms in an area at high risk for residential fire related injuries would reduce morbidity and mortality. In the first four years after the smoke alarm giveaway program, the target population experienced an $80 \%$ reduction in the injury rate compared with an $8 \%$ increase in the rest of Oklahoma City. ${ }^{12}$ Others have evaluated the effectiveness of smoke alarm programs in terms of an increase in the prevalence of functioning smoke alarms. ${ }^{13} 14$ However, none of these evaluations have examined the cost effectiveness of smoke alarm programs. This study estimates the costs and benefits over the five years after the Oklahoma City smoke alarm giveaway program.

\section{The Oklahoma City program}

In September 1987, the Oklahoma State Department of Health began statewide surveillance for burn injuries that resulted in hospitalization or death. Surveillance data from September 1987 through April 1990 indicated that an area in south Oklahoma City had a residential fire injury rate 2.6 times higher than that for the rest of the city. This part of the city became the target area. According to the 1990 United States census, the target area included $16 \%$ (73 301 persons) of the population of 
Table 1 Effectiveness of the LRFIPP in preventing fires and fatal and non-fatal residential fire related injuries

\begin{tabular}{|c|c|c|c|c|c|}
\hline \multirow[b]{2}{*}{ Outcome } & \multicolumn{2}{|c|}{ Average number per year } & \multirow[b]{2}{*}{$\%$ Change } & \multirow{2}{*}{$\begin{array}{l}\text { Net \% } \\
\text { changef }\end{array}$} & \multirow{2}{*}{$\begin{array}{l}\text { Injuries } \\
\text { prevented } \\
\text { per year }\end{array}$} \\
\hline & Pre-intervention * & Post-interventiont & & & \\
\hline \multicolumn{6}{|l|}{ Fires } \\
\hline Target area & 224.25 & 171.20 & -23.66 & -6.08 & 13.64 \\
\hline Rest of city & 693.00 & 571.20 & -17.58 & - & - \\
\hline \multicolumn{6}{|l|}{ Fatalities } \\
\hline Target area & 6.00 & 0.60 & -90.00 & -67.04 & 4.02 \\
\hline Rest of city & 6.75 & 5.20 & -22.96 & - & - \\
\hline \multicolumn{6}{|c|}{ Non-fatal fire related injuries } \\
\hline Target area & 5.25 & 1.20 & -77.14 & -92.70 & 4.87 \\
\hline Rest of city & 6.75 & 7.80 & +15.56 & - & - \\
\hline
\end{tabular}

*September 1987 to April 1990.

†May 1990 to April 1995.

$\ddagger$ Per cent change in target area minus per cent change in rest of city.

Oklahoma City (444 719 persons) that resided in $16 \%$ (34 945) of the city's dwellings (excluding apartments). However, this population experienced $45 \%$ of the residential fire related injuries in Oklahoma City. Compared with the rest of the city, the target area had a lower median household income, lower property values, and poorer quality of housing. The number of persons per occupied dwelling was the same as in the rest of the city.

In addition to higher residential fire related injury rates, the sources of fire related injuries in the target area exhibited a different distribution than that for the rest of the city. Forty seven per cent of residential fire related injuries in the target area resulted from fires started by children playing with fire, compared with $8 \%$ in the rest of the city. Fires from cigarette smoking caused $17 \%$ of the residential fire related injuries in the target area compared with $11 \%$ in the rest of the city. ${ }^{12}$

The Lifesavers Residential Fire Injury Prevention Program (LRFIPP) was designed to reduce the rate of residential fire related injuries and deaths in the target area. Homes without functioning smoke alarms in the target area were eligible for the program. A survey conducted before the program began estimated that almost 12000 homes (34\%) in the target area did not have functioning smoke alarms. ${ }^{12}$ A coalition of community agencies and volunteers, including the state and local health departments, the local chapter of the American Red Cross, and the Oklahoma City Fire Department, distributed smoke alarms doorto-door in the target area from May through November 1990. The door-to-door program, one of four types of programs tested during May 1990, was determined to be the most effective. ${ }^{15}$ Recipients of the smoke alarms also received educational material on how to install and maintain their alarms and how to prevent and escape from residential fires. The program distributed 10100 alarms to 9291 households, reaching an estimated $78 \%$ of the target households.

\section{Methods}

STUDY DESIGN

We conducted a cost effectiveness analysis of the LRFIPP in Oklahoma City. The study attempted to capture reductions in medical costs and productivity losses associated with fatal and non-fatal residential fire related injuries. Program costs included smoke alarms and batteries, educational materials, paid personnel and volunteers, administrative expenses, and implementation and follow up activities.

The study was conducted from the societal perspective, in which all program and medical costs and productivity losses from fire related injuries are included. This was done to examine the total value of the program to society. To examine the impact of the program on health care expenditures, the study was also conducted from the health care system perspective, in which only public agency program costs and medical costs from fire related injuries are included. We included the estimated costs and outcomes of the program generated from May 1990 to April 1995. Productivity losses associated with the deaths prevented during that time period extend for the potential life expectancy of an individual. All costs are reported in 1990 United States dollars. Costs that would have occurred after 1990 are discounted at 3\% annual rate. Medical costs obtained before 1990 were converted using the "medical care" component of the United States Consumer Price Index. ${ }^{16}$ Other pre-1990 costs were converted using the "all items" component. ${ }^{16}$

\section{PROGRAM EFFECTIVENESS}

We used two measures of effectiveness in this analysis: fatal and non-fatal residential fire related injuries prevented (table 1). A residential fire related injury was defined as a burn or smoke inhalation injury (International Classification of Diseases, 9th revision, clinical modification, codes 940.0 to 949.9 or 987.9 ) caused by a fire in an occupied dwelling resulting in hospitalization or death of a resident. ${ }^{12}$ Using Oklahoma burn injury surveillance data, we calculated the average annual number of fires and fatal and non-fatal residential fire related injuries that occurred in the target area and in the rest of the city during the period before the intervention (September 1987 to April 1990) and again for the five year period after the program had been implemented (May 1990 to April 1995). We calculated the per cent change in each outcome measure from preintervention to post-intervention. To estimate

Table 2 Undiscounted LRFIPP and participant costs, 1990-92*

\begin{tabular}{llll}
\hline & \multicolumn{2}{l}{ Year } & \\
\cline { 2 - 4 } Cost category & 1990 & 1991 & 1992 \\
\hline Personnel & & & \\
$\quad$ Paid & $\$ 145113$ & $\$ 70817$ & $\$ 72771$ \\
$\quad$ Volunteer & 15408 & 0 & 2170 \\
Office expenses & 30256 & 10049 & 5553 \\
Contractual expenses & 25250 & 10500 & 10500 \\
Transportation & 36587 & 2386 & 0 \\
Evaluation & 2720 & 2720 & 2720 \\
Smoke alarms & 42100 & 10233 & 8832 \\
Batteries & 4950 & 10100 & 0 \\
$\quad$ Program purchase & 490 & 4218 \\
$\quad$ Participant purchase & 0 & 0 & 0 \\
Educational material & 3691 & 0 & \\
\hline
\end{tabular}

*The only costs incurred after 1992 were $\$ 4218$ per year for participants' battery purchases in 1993-95 and $\$ 10000$ for the fourth year evaluation in 1994 . 
the proportion attributable to the LRFIPP, we calculated the net per cent change in the target area by subtracting the per cent change that occurred in the rest of the city. We then used the net per cent change in the three outcome measures to estimate the average annual number of fires, fatal and non-fatal residential fire related injuries prevented. We assumed in this analysis that these outcomes would have been prevented if the LRFIPP had not been implemented.

PROGRAM COSTS

We collected and calculated program costs for the five years of the analysis (table 2). Program costs were incurred during three program phases-planning, implementation, and maintenance - and were recorded for the year in which they occurred. The planning phase included the target area survey to determine smoke alarm prevalence and testing to determine the best distribution program. The implementation phase was the period during which smoke alarms and educational materials were distributed in the target area. The maintenance phase included both the postcard battery reminder program and an evaluation of alarm installation and function at participants' homes, conducted in the first, second, and fourth year of the program. Evaluations included the distribution of smoke alarms and batteries to survey homes without functioning smoke alarms, which contributed to program effectiveness. Therefore, we included evaluation costs in this analysis.

The costs for smoke alarms included those distributed both during the initial giveaway and during the evaluations. The costs for batteries included those distributed by the LRFIPP during the initial giveaway, replacement batteries distributed by the LRFIPP in the second and fourth year, and replacement batteries purchased by alarm recipients. Participants incurred battery replacement costs beginning in the third year of the program. We assumed that $42 \%$ of program participants replaced their batteries each year at a cost of $\$ 1$ per smoke alarm. The replacement rate is based on the 1994 evaluation of the LRFIPP, ${ }^{12}$ which reported a $72 \%$ annual battery replacement rate in the $58 \%$ of households participating in the evaluation that had at least one working alarm. In the initial distribution, 10100 smoke alarms were given to 9291 households, so we assumed that there were 1.09 alarms per household. ${ }^{12}$

The costs for volunteers were calculated by using the hourly wage the program would have paid someone to do the volunteer job. Contractual expenses included the costs for the participating burn centers and the cost to produce a promotional video. Transportation expenses included the canvassing minivan and the cost associated with using fire engines to distribute educational materials and smoke alarms.

COSTS OF FATAL AND NON-FATAL RESIDENTIAL FIRE RELATED INJURIES

The costs for fatal and non-fatal injuries were estimated from the costs incurred by persons in the target area with residential fire related injuries during the pre-intervention period (table 3). Of the 30 persons injured, 14 were hospitalized and survived, five were hospitalized but died, three were transported to the hospital but died either en route or in the emergency department, and eight died at the scene of the fire.

\section{MEDICAL COSTS}

Of persons hospitalized with non-fatal residential fire related injuries, $93 \%$ were transported to the hospital by ambulance. A friend or family member drove the remaining $7 \%$. Of persons with fatal residential fire related injuries, $50 \%$ were transported to the hospital and died either during transport, in the emergency room, or after admission.

Hospital costs for persons with both fatal and non-fatal residential fire related injuries requiring hospitalization were estimated from charges for their initial hospitalization. Charges were obtained from a review of hospital financial records for 13 of the 14 patients with nonfatal injuries and four of the five patients with fatal injuries admitted to Oklahoma City hospitals. To convert charges to costs, we used the American Hospital Association's ProPAC 1990 cost-to-charge ratio of 1.482 for Oklahoma hospitals. Hospital financial records did not include all professional services, so we used a ratio of 0.21 in professional services for every dollar of hospitalization to estimate the cost for inpatient physician visits. ${ }^{3}$ Because medical costs incurred after the initial hospitalization, such as follow up physician visits, rehospitalizations, outpatient visits, rehabilitation, and prescriptions, were not available, we used a multiplier of 0.75 of the cost of the initial hospitalization, including professional services, to estimate these costs.

The average length of stay for survivors was 14.6 days. The mean cost for the initial hospitalization was $\$ 14542$. Of the four patients who were admitted to the hospital but died, three were hospitalized for 20 days or longer.

Table 3 Average costs of fatal and non-fatal fire related injuries

\begin{tabular}{ll}
\hline Cost category & $\begin{array}{l}\text { Average cost } \\
(1990 \$)\end{array}$ \\
\hline $\begin{array}{l}\text { Non-fatal fire related injuries (cost per person) } \\
\quad \text { Medical costs }\end{array}$ & \\
$\quad$ Hospital & $\$ 14542$ \\
$\quad$ Inpatient physician visits & $\$ 3054$ \\
$\quad$ Other medical costs & $\$ 13195$ \\
Ambulance transport & $\$ 524$ \\
Total medical costs & $\$ 31317$ \\
Productivity losses (four months) & $\$ 7800$ \\
Fatalities (cost per person) & \\
$\quad$ Medical costs of hospitalized fatality† & $\$ 103713$ \\
$\quad$ Hospital & $\$ 21780$ \\
$\quad$ Inpatient physician visits & $\$ 564$ \\
Ambulance transport & $\$ 126056$ \\
Total medical costs of hospitalized fatality & $\$ 39185$ \\
Average medical cost for all fatalities $\ddagger$ & $\$ 764797$ \\
Productivity losses &
\end{tabular}

*Average ambulance transport cost for non-fatal injuries is based on a $93 \%$ transport rate.

†Nineteen per cent of all fatalities were hospitalized.

IIncludes the $50 \%$ of fatalities who died at the fire and, thus, incurred no medical costs and the $31 \%$ who died during transport or in the emergency room and only incurred transport costs. 
The mean cost per hospitalization was $\$ 103$ 713. Because hospital costs were not available for persons who died in the emergency department, we included only ambulance transport costs.

PRODUCTIVITY LOSSES

Productivity losses for persons who died of residential fire related injuries during the pre-intervention period represent the present value of potential lifetime earnings, including the imputed value of time spent on housekeeping activities, based on the person's age at death. Productivity losses were calculated for the 1990 United States employed population, weighted by sex and discounted at $3 \% .{ }^{17}$ Because we did not have data on work time lost for non-fatal injuries, we obtained estimates from the literature. ${ }^{18}{ }^{19}$ We used the more conservative estimate of the two published studies, four months lost. ${ }^{18}$ Using 1990 annual mean earnings and the imputed value of housekeeping activities, weighted by age and gender and spread over 365 days, we estimated that the average value of a lost work day was $\$ 65 .^{17}$

\section{SENSITIVITY ANALYSES}

We performed single and multivariable sensitivity analyses on all variables in the model to examine the impact of changes in their values on cost effectiveness. Because we used 1990 program and medical costs and productivity losses to remain consistent with the intervention study period, we performed sensitivity analyses to examine the potential effects of changes in costs from 1990 to 2001 . We also performed sensitivity analyses to examine the effect of underestimating or omitting long term medical and caregiver costs. To improve the generalizability of the results, we performed break-even analyses on variables whose values were likely to change in other smoke alarm programs and populations including the prevalence of residential fatal and non-fatal fire related injuries and program effectiveness.

\section{Results}

Results of the analysis are presented in table 4 . We estimated that, compared with no program, in five years the LRFIPP prevented 20 fatal and 24 non-fatal residential fire related injuries.

Table 4 Discounted program costs and savings associated with the LRFIPP, 1990-95

\begin{tabular}{ll}
\hline Program costs & \\
$\quad$ LRFIPP costs & 497936 \\
Volunteer time and participant costs & 32675 \\
Total program costs & 530611 \\
Costs of residential fire related injuries & \\
$\quad$ Medical costs & 1448188 \\
Productivity losses & 14292095 \\
Total fire related costs prevented & 15740283 \\
Net cost: societal perspective & 15209673 \\
Net cost: health care system perspective & 950253 \\
Program effectiveness & \\
Non-fatal injuries & 24 \\
Fatal injuries & 20 \\
Total injuries prevented & 44 \\
Cost per injury prevented: societal and & Savings \\
health care system perspectives & \\
\hline
\end{tabular}

${ }^{\star}$ Net $\operatorname{cost}=$ total fire related costs prevented-total program costs.

†Net cost $=$ medical costs-LRFIPP costs.
Key points

- Oklahoma City's Lifesavers Residential Fire and Injury Prevention Program effectively reduced fatal and non-fatal residential fire related injuries and was cost saving.

- Communities that have areas with high rates of residential fire related injuries should consider investing in programs to increase smoke alarm use.

- Smoke alarm education and giveaway programs are effective at decreasing fatal and non-fatal residential fire related injuries and can save money.

- Because residential fire related injuries are serious, expensive, and often long lasting, even a small decrease in the injury rate more than pays for programs to increase smoke alarm use.

The total discounted cost of the LRFIPP for the five year period was $\$ 531000$, of which $58 \%$ (\$306 000) was spent during the first year. The Oklahoma State Department of Health, the Oklahoma City Fire Department, and the American Red Cross contributed approximately $96 \%$ (\$498 000) of the total costs. Program volunteers (who helped to distribute educational materials and smoke alarms) and participants (who replaced batteries) contributed the remainder. In the five years after implementation, we estimated that the LRFIPP prevented almost $\$ 1.5$ million in medical costs and over $\$ 14$ million in productivity losses.

The program was cost saving from both the societal and the health care system perspectives. The net costs from the societal and health care system perspectives were $\$ 15$ million and $\$ 1$ million respectively. By the second year, medical costs averted had offset program costs.

The results of the analysis from both perspectives were not sensitive to small changes in the variable values. From the societal perspective, no reasonable changes in variable values would cause program costs to exceed the monetary benefits.

From the health care system perspective, either the program costs would have to double or the program effectiveness would have to decrease by at least $64 \%$ before the program would cease to be cost saving. Increases in medical costs from either inclusion of omitted costs or from inflation only increased the cost effectiveness of the program. The program would be cost saving in communities with residential fire related injury prevalence rates as much as $80 \%$ lower than the Oklahoma City program.

\section{Discussion}

The LRFIPP has proven to be an effective and economically beneficial program for preventing fatal and non-fatal residential fire related injuries as well as reducing property damage and costs to the Oklahoma City Fire Department. The rates of residential fires and related 
injuries and deaths have decreased substantially since the program began and they remain low. We do not know how much of this decrease is attributed to the higher prevalence of functioning smoke alarms or to the educational campaign that accompanied the giveaway program, but the combination of the two programmatic components was highly effective. Sensitivity analysis on the program's effectiveness indicates that, even in areas with initially lower rates of residential fires and fire related injuries or higher smoke alarm prevalences, similar programs could produce public health improvements and positive economic returns.

To our knowledge, this study is the first cost effectiveness study of a program designed to increase the prevalence of functioning smoke alarms in an area at high risk for residential fire related injuries. Many communities have programs designed to increase smoke alarm use, and many strategies have been employed, including distribution of smoke alarms at public sites, house-to-house canvassing, educational campaigns, and battery reminder programs. However, only a handful have been evaluated for their effectiveness and cost, even though community planners need this information to design programs best suited for their local conditions and resources. ${ }^{13-15} 20$

This study has several limitations. We did not include many of the benefits associated with the program because data were unavailable. We did not fully capture the extensive medical costs associated with the long term recovery of persons who were severely burned, although our estimates of the medical costs fall within the range of those in the published literature. ${ }^{1921}$ We also did not include any of the emergency room costs for persons who were hospitalized or capture any of the medical costs for persons who received emergency or outpatient care but were not admitted. However, Miller and Levy estimate that hospitalization accounts for 80 percent of all medical costs of fire related injuries. ${ }^{19}$ We also did not include any of the costs associated with pain and suffering or costs borne by families and caretakers of the persons injured.

We also omitted other costs associated with residential fires because data were lacking. Early detection and, consequently, faster fire department response may have led to decreased structural damage and have provided residents with more time to remove possessions. We also did not include costs to relocate displaced residents and to provide them with basic necessities or the costs borne by the many public service agencies which become involved as the result of a residential fire including the local fire department, emergency medical services, police department, and medical examiner's office. However, including these costs would only have increased the economic benefits of the program.

We may have overestimated the cost of the LRFIPP because we included the costs of the evaluations performed at three, 12 , and 48 months. Because these evaluations contributed to the effectiveness of the program we could not omit them. We did not include the cost of burn injury surveillance, which is critical in designing an effectively targeted program.

Although the rate of residential fire related injuries decreased substantially in the target area, it is disturbing that the evaluation performed four years after implementation of the program showed that only $58 \%$ of participating households had a functional smoke alarm. ${ }^{12}$ A similar pattern is now apparent nationwide. While $94 \%$ of households in the United States reported having at least one smoke alarm, one out of five households equipped with smoke alarms has none working. ${ }^{622} 23$ Lower socioeconomic households appear to be 1.5 times more likely to have inoperable smoke alarms. ${ }^{22}$ The cost and benefits of strategies designed to increase the longevity of program effectiveness-such as hard wired smoke alarms, alarms with lithium batteries, and ongoing battery reminder programs - should be evaluated, particularly among high risk populations.

Communities that have areas with high rates of residential fire related injuries should consider investing in programs similar to the LRFIPP. Because residential fire related injuries are serious, expensive, and often long lasting, even a small decrease in the injury rate more than pays for programs to increase smoke alarm use.

This work was supported in part by a grant (\#R49/ CCR603696) from the Centers for Disease Control and Prevention.

1 Hall JR. Fire in the USA and Canada, international fire comparison report. Quincy, MA: National Fire Protection Association, 1997

2 Baker SP, O'Neill B, Ginsburg J, et al. The injury fact book. 2nd Ed. New York, NY: Oxford University Press, 1992.

3 Rice DP, McKenzie EJ, and Associates. Cost of injury in the United States. a report to Congress. San Francisco, CA: Institute for Health and Aging, University of California and Injury Prevention Center, The Johns Hopkins University,

4 National Center for Health Statistics. Public use data tape documentation. Compressed mortality file, 1996. Hyattsville, MD: Centers for Disease Control and Prevention, 1999 .

5 Karter MJ Jr. 1997 fire losses in the United States. National Fire Protection Association fournal 1999;93:88-95.

6 Deaths resulting from residential fires and the prevalence of smoke alarms-United States, 1991-1995. MMWR Morb Mortal Wkly Rep 1998;38:803-6.

7 Runyan CW, Bangdiwala SI, Linzer MA, et al. Risk factors for fatal residential fires. N Engl F Med 1992;327:859-63.

8 Ballard JE, Koepsell TD, Rivara FP, et al. Descriptive epidemiology of unintentional residential fire injuries in King County, WA, 1984 and 1985. Public Health Rep 1992;107: 402-8.

9 Patetta MJ, Cole TB. A population-based descriptive study of housefire deaths in North Carolina. Am $\mathcal{F}$ Public Health 1990;80:1116-7.

10 Council on Scientific Affairs. Preventing death and injury from fires with automatic sprinklers and smoke detectors. FAMA 1987;257:1618-20.

11 Fire Administration. Fire in the United States 1983-1987. 7th Ed. Emmitsburg, MD: Fire Administration, 1990.

12 Mallonee S, Istre GR, Rosenberg M, et al. Surveillance and prevention of residential-fire injuries. $N$ Engl $\mathcal{F} \mathrm{Med}$ 1996;335:27-31

13 Shults RA, Sacks JJ, Briske LA, et al. Evaluation of three smoke detector promotion programs. Am F Prev Med 1998; 15:165-71.

14 Jernigan W. Keeping the smoke detectors operational: the Dallas experience. Fire f 1987;81 (July/August):57-63.

15 Douglas MR, Mallonee S, Istre GR. Comparison of community based smoke detector distribution methods in an urban community. Inj Prev 1998;4:28-32.

16 US Bureau of Labor Statistics. CPI Detailed Report. January 1995.

17 Haddix AC, Teutsch SM, Shaffer PA, et al. Prevention effectiveness: a guide to decision analysis and economic evaluation. New York, NY: Oxford University Press, 1996. 
18 Fletchall S, Hickerson WL. Quality burn rehabilitation: cost-effective approach. $\mathcal{F}$ Burn Care Rehabil 1995;16:539cost-

19 Miller TR, Levy DT. Cost outcome analysis in injury prevention and control: a primer on methods. Inj Prev 1997;3:288-93.

20 DiGuiseppi C, Slater S, Roberts I, et al. The "Let's Get Alarmed!" initiative: a smoke alarm giveaway programme. Inj Prev 1999;5:244-5.
21 Matthews JJ, Supple K, Calistro A, et al. A burn center costreduction program. F Burn Care Rehabil 1997;18:358-63.

22 Smith C. Smoke detector operability survey - report on findings. Bethesda, MD: US Consumer Product Safety Commission, as revised, October 1994.

23 Douglas MR, Mallonee S, Istre GR. Overestimation of functioning smoke alarm prevalence: a comparison of results of a telephone survey and a household survey. $A m \mathcal{F}$ Public Health 1999;89:1112-14.

\section{Good health pays off for Xerox. Four year study shows those in wellness plan reduced on-job injuries}

Employers may have another reason to encourage employees to stay fit, trim, and healthy: reducing the $\$ 128$ billion lost each year to workplace injuries. For years, advocates of workplace wellness programs have promoted them as a way to reduce the cost of health care and employer-financed health insurance. Now, a four year study of Xerox Corp workers has found significant reduction in the frequency and seriousness of workplace injuries among those who participate in a wellness program.

"Those people who are healthier have fewer injuries", lead researcher Shirley Musich of the University of Michigan Health Management Research Center said Tuesday.

The study examined on-the-job injuries among 3338 workers at a Xerox's Rochester, NY, manufacturing complex in 1996-99. The results were published in the July issue of the fournal of Occupational and Environmental Medicine.

Of the group, 943 participated in 1998 in the company's health risk appraisal program, a key part of its employee wellness plan. The health risk appraisal evaluated the workers' health risks such as smoking, obesity, drug and alcohol use, high blood pressure, life and job dissatisfaction. It is designed to steer them toward a healthier lifestyle.

"What companies like Xerox want to know is, does this program have value?" Musich said. "What does the company gain in spending money on employee wellness".

The answer, according to the study, is yes, such programs do have value because they save considerably more than they cost. Among those who participated in the health risk appraisal, $5.6 \%$ made workers compensation claims, compared with $8.9 \%$ of non-participants. And when they did get hurt on the job, the health appraisal participants had an average cost per injury of $\$ 6506$, compared with $\$ 9482$ for non-participants, the study found.

"Over a two-year period, we found a five-to-one return on investment", said Deborah Napier, health management director for Xerox and a coauthor of the study.

(David Goodman, Associated Press) 